\title{
Studies on the Liver to Kidney
}

\section{Switch of Erythropoietin Production}

\author{
Esmail D. Zanjani, Joao L. Ascensao, Philip B. McGlave, \\ MUSSA BANISADRE, and ROBERT C. ASH, Veterans Administration \\ Medical Center, Departments of Medicine and Physiology, University of \\ Minnesota School of Medicine, Minneapolis, Minnesota 55417
}

\begin{abstract}
A B S T R A C T Although the liver is the major site of erythropoietin (Ep) production in the fetus, this function is assumed by kidneys in the adult. The mechanisms underlying the liver to kidney switch of Ep formation are not understood. We studied the natural progression of this transition in sheep by measuring Ep production in response to anemia in normal and bilaterally nephrectomized fetal and newborn sheep beginning at about $80 \mathrm{~d}$ gestation (normal gestation:
\end{abstract} $140 \mathrm{~d}$ ). Removal of both kidneys before induction of anemia did not affect $\mathrm{Ep}$ formation up to about $120 \mathrm{~d}$ of gestation. A significant reduction $(29 \%, P<0.02)$ in Ep synthesis was first noted at about $130 \mathrm{~d}$ of gestation (initiation of switch). This level of nephrectomyinduced reduction of $\mathrm{Ep}$ formation persisted until about $15 \mathrm{~d}$ after birth. Thereafter, bilateral nephrectomy caused further significant decreases $(P<0.05)$ in Ep production, gradually resulting in near total absence of Ep production at about day 40 postpartum (completion of switch). Chronic administration of testosterone (12 $\mathrm{mg} / \mathrm{wk})$ or estradiole benzoate $(1.5 \mathrm{mg} / \mathrm{d}, 5 \mathrm{~d} / \mathrm{wk})$ to the fetus/newborn beginning at 85-90 d of gestation enhanced or suppressed erythropoiesis, respectively, but failed to affect the time at which the liver to kidney switch was initiated and/or completed. By contrast, a significant delay $(P<0.001)$ in the onset, but not completion of the switch occurred in animals that were either thyroidectomized or rendered chronically anemic beginning in the second third of the gestation period. Administration of thyroxin $(1.2 \mathrm{mg} / \mathrm{d}, 5 \mathrm{~d} / \mathrm{wk})$ to thyroidectomized fetus/newborns not only prevented the delay in the initiation of the switch, but also accelerated the rate at which the switch was completed. These results demonstrate that in sheep $(a)$ the liver to kidney switch of Ep production is initiated in utero during the last third of the gestation period, but is

\footnotetext{
Address reprint requests to Dr. Zanjani.

Received for publication 24 September 1980 and in revised form 5 December 1981 .
}

completed after birth, $(b)$ this transition occurs gradually; the assumption of Ep producing capacity by the kidney is not preceded by an abrupt loss of hepatic Ep formation; and $(c)$ the switch is not affected by changes in sex hormone levels during the prenatal-postnatal growth periods, but is profoundly influenced by alterations in thyroid hormone and oxygen supply-demand levels.

\section{INTRODUCTION}

Erythropoietin $(E p)^{1}$ is the primary regulator of erythropoiesis in the mammalian fetus and the adult $(1,2)$. In the adult, the kidney represents the major site of Ep production (3). By contrast, during fetal and early neonatal periods, the liver is the primary Ep producing organ (4). The switch from liver to kidney production of Ep occurs soon after birth (5). Although the switch is accompanied by the effective loss of Ep formation by the liver, a number of studies have demonstrated that the hepatic system continues to be involved in Ep production in the adult but at a significantly reduced level $(6,7)$. This is evident from the fact that under most conditions the hepatic (extrarenal) source can produce only about 5-15\% of the Ep normally evoked in intact adults $(3,6,7)$. Recent studies by Erslev et al. (8), however, suggest that in response to more severe hypoxic stimulation, extra-renal Ep production may reach levels comparable to those of renal Ep formation in the adult, and presumably, liver Ep formation in the fetus.

The mechanism(s) underlying the liver to kidney switch in Ep production is not known. In this regard, Lucarelli et al. (5) have indicated that the onset and/ or completion of the liver to kidney switch may be correlated with the degree of maturity of the fetus/

\footnotetext{
${ }^{1}$ Abbreviations used in this paper: DT, testosterone cyclopentyl propionate (depo-testosterone); EB, estradiole benzoate; Ep, erythropoietin; $\mathrm{LT}_{4}$, L-thyroxin.
} 
newborn. However, no information describing the natural progression of this transition is currently available.

In the present study, we have examined the development of the liver to kidney switch in sheep and studied the influence of sex and thyroid hormones and chronic hypoxia on this process. The results demonstrate that the liver to kidney switch is initiated in utero, occurs independently of sex-hormonal influences, but may be significantly affected by thyroid hormone and chronic hypoxia.

\section{METHODS}

These studies were conducted in random bred sheep. Pregnant ewes with confirmed dates of conception were obtained from local suppliers, observed, acclimated for $5 \mathrm{~d}$, and then fasted for $24 \mathrm{~h}$ before surgery. Progesterone (lipo-lutin, 20 mg., Parke, Davis and Co., Detroit, Mich.) was administered intramuscularly on the day before surgery and daily thereafter to animals used in chronic studies. We prepared fetuses in all groups for the study by inserting a catheter into each of two fetal femoral arteries, as described (9). Other surgical and experimental manipulations are detailed below.

Anemia induced by a single bleeding of the fetus via the catheters, and of the newborn via the jugular vein was used to stimulate Ep production in all animals. The volume of blood withdrawn varied from one animal to another but usually represented about $1.6-2 \%$ of the animal's estimated body weight. Blood drawn into heparinized syringes was immediately centrifuged $(1,500 \mathrm{~g}, 10 \mathrm{~min}$, room temperature $)$ and erythrocytes were discarded. $6-12$-ml aliquots of plasma were saved for Ep determination and the remainder reinfused into the fetus/newborn. The anemia was induced immediately after catheter emplacements and/or organ removal. Plasma samples for Ep determinations were obtained $6 \mathrm{~h}$ after the bleeding.

We have previously demonstrated that the removal of amounts of blood corresponding to $1.6-2 \%$ of the body wt from the fetus and newborn sheep is a potent stimulator of $\mathrm{Ep}$ production resulting in the appearance of $1-2 \mathrm{IU} \mathrm{Ep} / \mathrm{ml}$ of plasma (4). In the present studies, the amount of Ep produced within $6 \mathrm{~h}$ in response to the bleeding ranged from $0.7-1.2$ IU Ep/ml of plasma in both the fetus and the newborn. This is well within the detection and quantitation range of the bioassay procedure used here (see below) which has a lower limit of sensitivity of $0.05 \mathrm{U}$ of Ep. This schedule of bleeding was used in all groups except those employed in studies designed to assess the effects of chronic hypoxia or hormone treatments on the liver to kidney switch. The schedules of surgery, hormone treatments, and bleeding for the latter groups are detailed below.

The exhypoxic polycythemic mouse bioassay was used to measure the Ep contents of all plasma samples (10). The plasma from each fetus was assayed separately using five mice per group. Samples were injected on day 5 posthypoxia, radioiron $(0.5 \mu \mathrm{Ci} /$ mouse $)$ was administered on day 7 , and the percentage erythrocyte- ${ }^{59} \mathrm{Fe}$ incorporation determined on day 10 . Normal plasma samples were assayed at a single concentration of $1 \mathrm{ml} /$ mouse. Each anemic plasma was assayed at concentrations of $0.25,0.5$, and $1.0 \mathrm{ml} /$ mouse. The percentage erythrocyte- ${ }^{59} \mathrm{Fe}$ incorporation values were converted into equivalent units of $\mathrm{Ep}$ by reference to standard curves established for International Reference Preparation of Ep.

In studies designed to establish the times at which the liver to kidney switch is initiated and/or completed (Fig. 1), groups of normal fetuses (ages: $80 \mathrm{~d}$ to birth) and newborns were bilaterally nephrectomized via a single ventral incision at the time of catheter emplacements (11). After skin closures, the fetus was replaced within the uterus, the uterine incisions closed around the catheters and the uterus returned to the abdomen. Immediately after maternal body wall and skin enclosures, each fetus (or newborn) was rendered anemic and Ep production determined $6 \mathrm{~h}$ later.

The effects of testosterone cyclopentyl propionate (DT: 12 $\mathrm{mg} / \mathrm{wk}$ ) and estradiole benzoate (EB: $1.5 \mathrm{mg} / \mathrm{d}, 5 \mathrm{~d} / \mathrm{wk}$ ) on the liver to kidney switch (Fig. 2) were determined by administering each hormone and/or the vehicle (propylene glycol) separately through subcutaneous catheters to fetuses that were surgically fitted with the catheters at about 85-90 d of gestation (12). At intervals shown in Fig. 2, groups of 2-3 fetuses each were bilaterally nephrectomized and bled as described above. The role of thyroid hormone on the liver to kidney transition was examined as follows. Fetuses were thyroidectomized via a midline incision over the neck (13) at about 85-90 d of gestation. In addition, each fetus was fitted with three separate subcutaneous catheters as described (12). No intravenous catheters were placed in the fetus at this time. The animals were divided into two groups. The fetuses in one group were given injections of $1.2 \mathrm{mg}$ thyroxin $\left(\mathrm{LT}_{4}\right)$ dissolved in $0.5 \mathrm{ml}$ of the vehicle $(0.0025 \mathrm{M} \mathrm{NaOH}$ in saline $) / \mathrm{d}$, $5 \mathrm{~d} / \mathrm{wk}$ for the duration of the study. The remaining fetuses were administered $0.5 \mathrm{ml}$ of the vehicle alone. At intervals shown in Fig. 3, two animals from each group were fitted with intravenous catheters immediately before removal of both kidneys. Ep production was assessed by rendering the fetus anemic as detailed above. At the termination of the study the tissues surrounding the thyroid gland in each fetus were examined microscopically to ensure the absence of gland tissue (13). The influence of chronic anemia on the liver to kidney switch (Fig. 5) in the fetus/newborn was studied as follows. Fetuses were operated on for insertion of intravenous catheters at about $100-110 \mathrm{~d}$ of gestation, and allowed to recover from surgery for $2 \mathrm{~d}$. Each fetus was rendered chronically anemic by bleeding following the schedule indicated below. On day 2 postsurgery, enough blood was removed from each fetus to decrease the circulating hematocrit from a mean of $33.2 \pm 2.1 \%$ to $20.8 \pm 1.2 \%$. The volume of blood removed to achieve this decrease corresponded to $\sim 2 \%$ fetal body wt. Each fetus was phlebotomized again at about 5-d intervals to maintain an average hematocrit of $20 \%$ in the fetus. In those fetuses allowed to be born, a similar degree of anemia was maintained by bleeding the newborn at $\sim 5-7-d$ intervals. Plasmas from these bleeding were saved and assayed for Ep activity. Since the high levels of Ep (Fig. 4) present in these fetuses and newborns (in response to chronic bleeding) could mask the standard Ep response to a single bleeding following nephrectomy/hepatectomy, each animal was transfused with washed maternal sheep erythrocytes $72 \mathrm{~h}$ before surgery was performed. The volume of erythrocytes given was sufficient to raise the animal's circulating hematocrit to $42 \%$ which is above the hematocrit values in normal fetus/newborns of comparable age. This increase in the circulating erythrocyte mass was enough to suppress Ep production in these animals; plasma samples obtained immediately before nephrectomy were devoid of detectable Ep activity. At intervals shown in Fig. 5, the animals were bilaterally nephrectomized or hepatectomized $3 \mathrm{~d}$ after the erythrocyte transfusion, and their Ep response to a single bleeding thereafter measured as outlined above. Hepatectomy in fetuses and newborn lambs was performed through an abdominal incision and involved the removal of about $95 \%$ of the total liver mass (determined by weighing the remaining tissue at the termination of the study). The pro- 
cedure involved the removal of all but a very small amount of hepatic tissue (remaining at the base) from every lobe of the liver. Subsequent steps were similar to those described for nephrectomized animals.

\section{RESULTS}

Because of the restriction imposed on us by the fact that only a limited number of pregnant ewes of appropriate gestational age were available in a given breeding season, it was not always possible to perform the studies on all the animals included in each experimental group at the same time. Results presented for each group have been obtained from animals studies as long as $3 \mathrm{yr}$ apart. However, in each case, an appropriate control was always included with each experimental animal studied. The controls, always agematched, received the same treatments as the study animals except for those manipulations that distinguished the experimental animals from controls. Thus, kidneys or livers in control fetuses and newborns were manipulated but not removed, or the animals received appropriate numbers of subcutaneous injections of only the vehicle solutions, whereas the bleeding schedules were similar for both groups. Plasmas from control and experimental animals were assayed for Ep activity using the same batch of polycythemic mice, and the results for experimental animals where appropriate were calculated to reflect the percentage of activity exhibited by the control plasma samples.

The various surgical manipulations resulted in the loss of a considerable number of animals initially used in each group. The highest mortality rate occurred in the chronic anemia group (38\%), and the lowest death rate occurred in the hormone-treated groups $(18 \%)$. The number of animals shown in the figures, therefore, reflect the number of surviving fetuses and newborns in each group. It should be noted that because of the high mortality rate encountered in these studies, the number of observations for some of the experimental points was limited to only two to three animals.

Results presented in Fig. 1 demonstrate that the removal of both kidneys before induction of anemia did not significantly affect Ep formation in the fetus up to about $120 \mathrm{~d}$ of gestation. A significant decrease $(P$ $<0.02$ ) in Ep production was first noted at $130 \mathrm{~d}$ of gestation. Thus, bilaterally nephrectomized 130-d-old fetal sheep exhibited, on the average, a $29 \%$ reduction in Ep production. This degree of nephrectomy-induced inhibition of Ep formation persisted until about $15 \mathrm{~d}$ postnatally (Fig. 1). The results presented in Fig. 1 also show that the role of the kidney in Ep formation in newborn lambs became progressively more significant with age, and within the next 15-25 d the kidneys assumed the primary role in Ep production. In this regard, bilateral nephrectomy nearly completely inhibited Ep formation in 35-40-d-old newborn lambs, as was

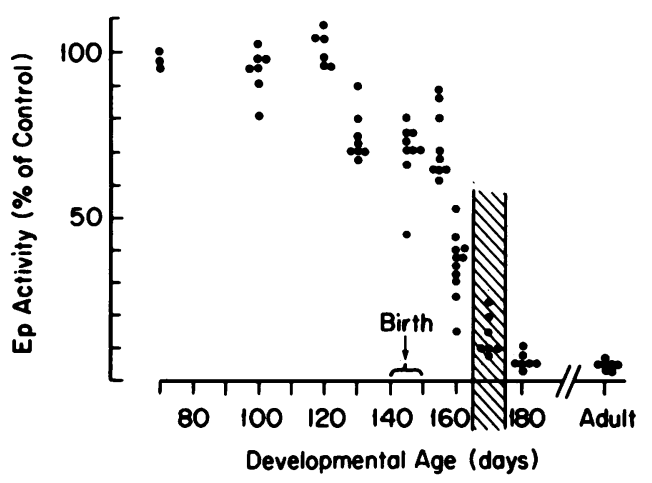

FIGURE 1 Ep production in bilaterally nephrectomized sheep fetuses and newborns. Plasma Ep activity was measured $6 \mathrm{~h}$ after the nephrectomized animal was stimulated by a single bleeding. Each dot represents results from a separate animal. The hatched bar delineates the period when kidneys become the major site of Ep formation in sheep. The results presented here reflect the proportion of $\mathrm{Ep}$ activity present in plasma samples obtained $6 \mathrm{~h}$ after a single bleeding from sham-operated controls of the same age. Representative actual plasma Ep levels (means) from which these percentages were derived were: Controls: days $80-180,0.8 \mathrm{IU} / \mathrm{ml}$; Experimentals: days $80-120,0.85 \mathrm{IU} / \mathrm{ml}$; day $130,0.60 \mathrm{IU} /$ $\mathrm{ml}$; day $160,0.30 \mathrm{IU} / \mathrm{ml}$; day $170,0.08 \mathrm{IU} / \mathrm{ml}$. In all cases controls and experimental animals were studied simultaneously.

the case in the adult sheep. These results suggest that in the New Zealand strain of sheep the liver to kidney switch in Ep synthesis is initiated during the last third of the gestation period and is completed by the time the animal is about $40 \mathrm{~d}$ old.

The effect of chronic administration of sex hormones on the liver to kidney switch is shown in Fig. 2. As we reported earlier (12), DT enhanced Ep production and erythropoiesis in fetal sheep. In the present studies, DT-treated fetuses and newborns exhibited elevated levels of circulating Ep that ranged from 0.18 to 0.35 IU Ep/ml of plasma. The plasma Ep level was determined for each animal before the induction of anemia (after nephrectomy) and this value was subtracted from the postbleeding Ep values before presentation of the experimental data in Fig. 2. Administration of EB resulted in significant suppression of erythropoiesis in the fetus/newborn. This was evident from decreased reticulocytosis $(2.3 \pm 0.3$ vs. $0.4 \pm 0.1 \%)$ and \% erythrocyte- ${ }^{59} \mathrm{Fe}$ incorporations $(27 \pm 4$ vs. $14 \pm 2 \%)$ determined in comparably treated animals of similar ages. The results presented in Fig. 2 show that chronic treatment with these steroids failed to affect either the time of the initiation of the switch or the rate at which the liver to kidney transition is completed. By contrast, a significant delay in the onset of the switch occurred in thyroid-deficient and chronically anemic fetuses. In animals that were thyroidectomized late in the second third of the gestation period, the change from liver to kidney did not commence until after birth (Fig. 3). 


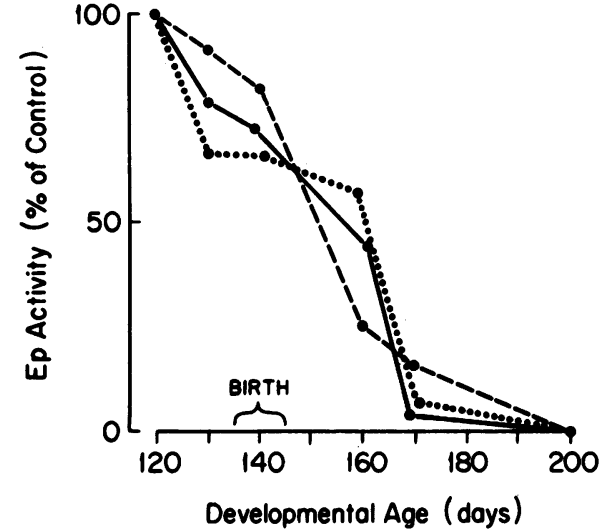

FIGURE 2 Effect of chronic administration of DT (dashed lined), EB (dotted line), or the vehicle propylene glycol (solid line) on the liver to kidney switch of Ep synthesis in sheep. Each point represents mean of results from two to three separate animals. These percentages were derived from actual values obtained by assaying the animals' plasmas in exhypoxic polycythemic mice (see text). Representative mean plasma Ep levels were: day 120: controls, $0.8 \mathrm{IU} / \mathrm{ml}$; DT, 1.4 $\mathrm{IU} / \mathrm{ml}$; EB, $0.45 \mathrm{IU} / \mathrm{ml}$; day 160: controls, $0.35 \mathrm{IU} / \mathrm{ml}$; DT, $0.30 \mathrm{IU} / \mathrm{ml}$; EB, $0.25 \mathrm{IU} / \mathrm{ml}$; day 170 , controls, $0.05 \mathrm{IU} / \mathrm{ml}$; DT, $0.25 \mathrm{IU} / \mathrm{ml}$; EB, $0.05 \mathrm{IU} / \mathrm{ml}$.

However, the time at which the transition was completed was not affected (Fig. 3). The overall production of Ep in response to bleeding was significantly reduced in thyroidectomized as well as in EB-treated animals throughout the study period. For example, the plasma Ep levels for EB-treated and thyroidectomized animals at age $120 \mathrm{~d}$ were 0.45 and $0.4 \mathrm{IU} / \mathrm{ml}$ respec-

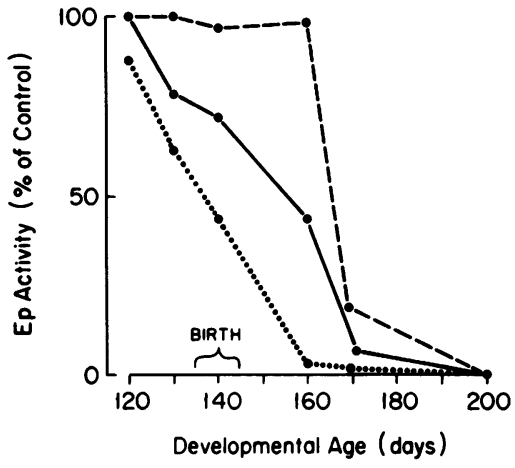

Figure 3 Role of thyroid hormone in the liver to kidney switch of erythropoietin (Ep) synthesis in sheep. Each point represents mean of results from two to three separate animals. Solid line: vehicle-treated normals; dashed line: vehicletreated thyroidectomized $\left(\mathrm{T}_{\mathrm{x}}\right)$ animals; dotted line: $\mathrm{LT}_{4^{-}}$ treated thyroidectomized animals. These percentages were derived from actual values obtained by assaying the animals' plasmas in exhypoxic polycythemic mice (see text). The values for euthyroid controls are the same as are shown in Fig. 2. The mean plasma Ep levels $(\mathrm{IU} / \mathrm{ml})$ for the groups were $\left(T_{x}\right.$ vs. $\left.L_{4}\right)$ : day $120,0.4$ vs. 1.2 ; day $130,0.45$ vs. 0.75 ; day 140 , 0.40 vs. 0.55 ; day $160,0.40$ vs. $<0.05$; day $170,0.07$ vs. $<0.05$. tively, while the amount of Ep present in $1 \mathrm{ml}$ of plasma obtained from normal fetuses of comparable age subjected to the same degree of phlebotomy-induced anemia was $0.8 \mathrm{IU}$. In contrast, both LT4 and DTtreated animals responded to bleeding by producing considerably higher amounts of Ep than would be anticipated. Administration of LT4 to the thyroidectomized animals prevented the delay in the initiation of the switch, but accelerated the rate at which the transition was completed (Fig. 3). Here again, it was necessary to subtract the prenephrectomy Ep values exhibited by LT4-treated animals' plasmas from the post-bleeding values since treatment of thyroidectomized animals with LT4 resulted in stimulation of Ep formation (0.1-0.2 IU Ep/ml plasma).

The data shown in Fig. 4 demonstrate that Ep production was significantly enhanced in the chronically anemic fetus/newborn throughout the study period. Thus, the level of anemia achieved by chronic bleeding produced a degree of hypoxia sufficient to provide the continuous stimulation of the Ep-producing system in these animals. The results depicted in Fig. 5 clearly indicate that the onset of the liver to kidney switch was significantly delayed in these chronically anemic animals. Thus bilateral nephrectomy did not cause a significant reduction in Ep formation until day 195. This represented about a 20-d delay in the initiation of the switch. This delay, however, did not persist despite continuous hypoxic stimulation of the newborn (Fig. 5). Fig. 5 also shows that the liver continued to function as the primary source of Ep throughout the study period; Ep production was effectively reduced by hepatectomy.

\section{DISCUSSION}

It is now well established that the primary organ responsible for Ep formation in the adult is different from the organ serving the same function in the fetus

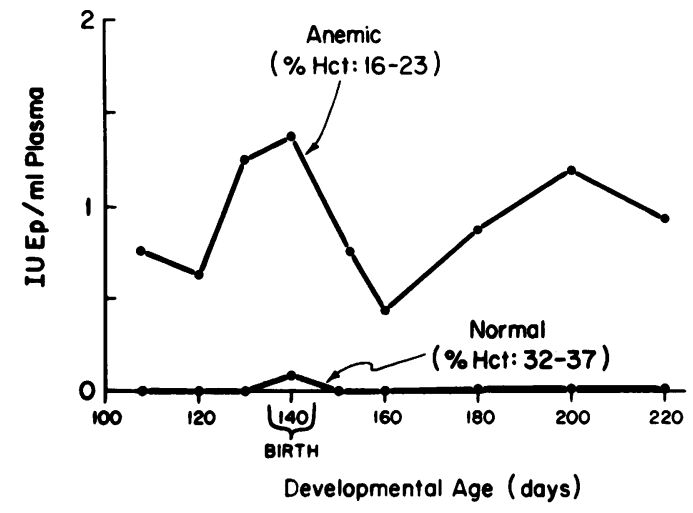

FIGURE 4 Effect of chronic anemia on Ep production in sheep fetuses and newborns. Each point represents mean of results from three to four separate animals. 


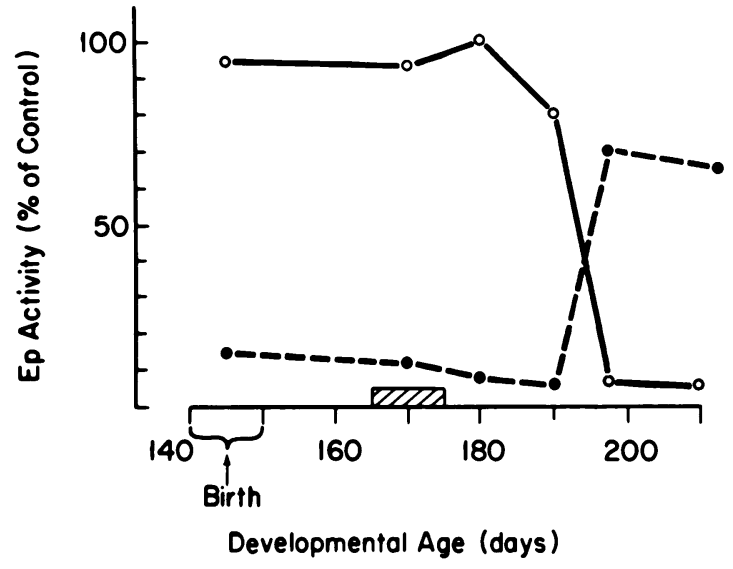

FIGURE 5 Effect of chronic anemia on the liver to kidney switch of Ep synthesis in sheep. Each point represents mean of results from three separate animals. Shaded area delineates period when kidneys assume the primary role in Ep formation in normal sheep. These percentages were derived from actual values obtained by assaying the animals' plasmas in exhypoxic polycythemic mice (see text). The mean plasma Ep levels (IU/ml) for the groups were nephrectomized (O) vs. hepatectomized $(O)$ : day $145,0.9$ vs. 0.1 ; day $170,0.85$ vs. 0.1 ; day $180,0.95$ vs. 0.05 ; day $190,0.7$ vs. $<0.05$; day 200 , 0.05 vs. 0.65 ; day $210,<0.05$ vs. 0.60 .

(1-8). During fetal stages of development Ep is produced mainly by the liver (4), whereas in the adult the kidneys assume this role (3). The mechanisms underlying this transition are not understood. Moreover, it is not known whether the processes leading to this change are initiated in utero or postpartum. Both possibilities find support in previously published findings $(5,14)$. In rats, the liver continues to function as the primary site of Ep formation at birth and for a time thereafter (14) leaving open the possibility that the initiation of the switch could occur before or after birth. On the other hand, studies by Lucarelli et al. (5) in guinea pigs suggest that the process may have been initiated in utero.

The results presented here demonstrate that the switch from liver to kidney production of $\mathrm{Ep}$ in sheep is first initiated sometime during the third gestation period close to birth. Thus, at about $130 \mathrm{~d}$ of gestation, bilateral nephrectomy resulted in a $15-30 \%$ decrease in Ep formation; the transition from liver to kidneys was completed about 2 mo later. Thereafter, the kidneys functioned as the major source of Ep synthesis. The initiation of the switch was not preceded by a sudden loss in hepatic Ep production. Rather, the acquisition of the Ep-producing function by the kidney appears to be accompanied by a gradual decrease in hepatic Ep formation; during most of the transition period both organs are involved in Ep synthesis.

It is possible that the initiation of the switch and/or the rate at which the transition is completed may be associated with endocrine changes that occur during the last third of the gestation period close to parturition (15). In this regard, sex and thyroid hormones have been shown to profoundly influence erythrocyte production in the fetus (12). The results of studies reported here suggest that despite their significant effect on erythropoiesis and Ep production, sex hormones did not exert a significant effect on the liver to kidney switch in sheep.

By contrast, thyroidectomy and thyroid hormone administration caused significant changes in the switch process. The onset of the liver to kidney switch was significantly delayed (by about $30 \mathrm{~d}$ ) in thyroidectomized animals (Fig. 3). The time at which the transition was completed, however, was not affected by the absence of the thyroid gland. Although thyroid hormone levels were not measured in the animals used here, several lines of evidence clearly indicated that the changes in the switch were caused by a true thyroid deficiency. In this regard, $(a)$ in each experimental animal, thyroidectomy was confirmed by microscopic examination of the removed glands, and of the surrounding neck tissues at the termination of the study; (b) the hypothalamic-pituitary-thyroidal axis in fetal sheep, like that of the human fetus, appears to be autonomous, so that by the third trimester (when these experiments were performed) fetal thyroid deficiency is not ameliorated by transplacental passage of maternal thyroid hormones (16); and (c) in agreement with others $(13,17)$, all but one of the animals in our study exhibited some degree of growth retardation. Moreover, replacement therapy by the chronic administration of LT4 to thyroidectomized fetuses prevented the delay in the initiation of the switch. It is interesting, however, that thyroid hormone administration also resulted in the acceleration of the rate at which the transition from the liver to kidneys was completed (Fig. 3).

It is possible that the thyroid hormone effect on the liver to kidney switch may be associated with the well established role of this hormone in body metabolism. Thus, the reduced tissue oxygen demand caused by decreased metabolism (presumably in effect in athyroid fetuses) may have somehow retarded the processes leading to the initiation and subsequent completion of the switch. Similarly, the increased oxygen demand in LT4-treated fetuses may have accelerated the process. The results presented here (Fig. 5), however, suggest that such a possibility is not likely. Chronically hypoxic fetus/newborn sheep exhibited a significant delay rather than acceleration of the switch. It is more likely that the role of the thyroid hormone in the liver to kidney switch is associated with the generalized effect of this hormone on fetal growth and development.

Although earlier studies in rats and rabbits had failed to establish a role of thyroid gland in prenatal growth and maturation (18), a number of experiments have 
demonstrated that this endocrine gland plays a significant role in the development of the sheep fetus $(13,17)$. The difference between these species of mammals appears to reside in the fact that in rats and rabbits fetal thyroid does not become functional until quite late in gestation, whereas in sheep, as well as in man, the thyroid begins functioning quite early in gestation (17). Thus, in sheep fetal thyroid deficiency is associated with impaired growth, retarded nervous system development, prolonged gestation, impaired maturation of wool follicles, and decreased growth and maturation of long bones (17). It is probable that thyroid hormone deficiency also resulted in impaired development of the liver and kidneys.

The discovery that the liver is the primary site of Ep formation in the fetus is compatible with the structural and functional aspects of fetal circulation. Oxygenated blood returning to the fetus from the maternal side of the placenta passes through the ductus venosus and partially bypasses the liver (19). Therefore, the blood which is most fully oxygenated does not go to the liver, but directly to the heart. The resultant relative hypoxia of the hepatic tissue may be somehow involved in the liver functioning as the primary Ep-producing organ in the fetus. The ductus venosus begins to close soon after birth and is occluded prior to the time the liver to kidney switch is completed. Whether the loss of the hepatic Ep-producing function is in some way associated with the functional state of the ductus venosus remains to be determined. The mechanism(s) triggering the acquisition of the Ep-producing function by the kidney is also not understood. The possibility exists that the initiation of renal Ep production late in the third gestation period may be in response to the greater demand for oxygen by the fetus during this period.

Although the tissue oxygen requirements for fetuses during intrauterine life are met satisfactorily under normal conditions of pregnancy as shown by data collected from healthy adults, Creasey et al. (20) have demonstrated that arterial blood $\mathrm{PO}_{2}$ in the fetus is significantly lower than that of the mother. In addition, although the placental blood volume in sheep and goats remains fairly constant during the last third of the gestation period, with the rapid growth of the fetus during this period, the placental blood volume assumes an ever decreasing ratio to the fetoplacental volume. The resulting relative decrease in the availability of oxygenated maternal blood to the fetus along with effects of placental aging might then lead to the sensing of a relative degree of hypoxia by the fetal oxygen receptors thus triggering the Ep-producing mechanism in the kidney.

\section{ACKNOWLEDGMENTS}

This work was supported by grants AM-24027 and CA-23021 from the National Institutes of Health, and by Veterans Administration research funds.

\section{REFERENCES}

1. Gordon, A. S. 1973. Erythropoietin. Vitam. Horm. 31: 105-174.

2. Zanjani, E. D., L. I. Mann, H. Burlington, A. S. Gordon, and L. S. Wasserman. 1974. Evidence for a physiologic role of erythropoietin in fetal erythropoiesis. Blood. 44: 285-290.

3. Jacobson, L. O., E. Goldwasser, W. Fried, and L. Plazak. 1957. Role of the kidney in erythropoiesis. Nature (Lond.). 179: 633-634.

4. Zanjani, E. D., J. Poster, H. Burlington, L. I. Mann, and L. R. Wasserman. 1977. Liver as the primary site of erythropoietin formation in the fetus. J. Lab. Clin. Med. 89: 640-644.

5. Lucarelli, G., A. Porcellini, C. Carnevali, A. Carmena, and F. Stohlman, Jr. 1968. Fetal and neonatal erythropoiesis. Ann. N. Y. Acad. Sci. 149: 544-559.

6. Fried, W. 1972. The liver as a source of extrarenal erythropoietin production. Blood. 40: 671-677.

7. Schooley, J. C., and L. J. Mahlmann. 1972. Erythropoietin production in the anephric rat. I. Relationship between nephrectomy, time of hypoxic exposure and erythropoietin production. Blood. 39: 31-38.

8. Erslev, A. J., J. Caro, E. Kansu, and R. Silver. 1980. Renal and extrarenal erythropoietin production in anaemic rats. Brit. J. Haematol. 45: 65-72.

9. Zanjani, E. D., E. Horger, A. S. Gordon, L. N. Cantor, and D. L. Hutchinson. 1969. Erythropoietin production in the fetal lamb. J. Lab. Clin. Med. 74: 782-788.

10. Zanjani, E. D., J. D. Lutton, R. Hoffman, and L. R. Wasserman. 1977. Erythroid colony formation by polycythemia vera marrow in vitro. Dependence on erythropoietin. J. Clin. Invest. 59: 841-848.

11. Zanjani, E. D., E. N. Peterson, A. S. Gordon, and L. R. Wasserman. 1974. Erythropoietin production in the fetus: role of the kidney and maternal anemia.J. Lab. Clin. Med. 83: $281-287$.

12. Zanjani, E. D., and M. Banisadre. 1979. Hormonal stimulation of erythropoietin production and erythropoiesis in anephric sheep fetuses. J. Clin. Invest. 64: 1181-1187.

13. Bhakthavathsalan, A., L. I. Mann, J. Ayromlooi, W. Kunzel, and M. Liu. 1977. The effects of fetal thyroidectomy in the ovine fetus. Am. J. Obstet. Gynecol. 127: 278-284.

14. Lucarelli, G., D. Howard, and F. Stohlman, Jr. 1964. Regulation of erythropoiesis. XV. Neonatal erythropoiesis and the effect of nephrectomy. J. Clin. Invest. 43: 2195-2203.

15. Challis, J. R. G., and G. D. Thorburn. 1975. Perinatal endocrine function and the initiation of parturition. $\mathrm{Br}$. Med. Bull. 31: 57-61.

16. Fisher, A. D. 1974. Fetal thyroid metabolism. Contemp. Obstet. Gynecol. 3: 47-61.

17. Thorburn, G. D., and P. S. Hopkins. 1973. Thyroid function in the foetal lamb. In Foetal and Neonatal Physiology. K. S. Comline, K. W. Cross, G. S. Dawes, and P. W. Nathanielsz, editors. Cambridge University Press, London, England. 488-507.

18. Jost, A. 1971. Hormones in development: past and prospects. In Hormones in Development. M. Hamburgh and E. J. W. Barrington, editors. Meredith Publishing Co., Des Moines, Iowa. 1-18.

19. Guyton, A. C. 1971. Textbook of Medical Physiology. W. B. Saunders Co., Philadelphia, Pa. 994-995.

20. Creasey, R. K., M. Drost, M. V. Green, and J. V. Morris. 1970. Determination of fetal, placental and neonatal blood volumes in sheep. Circ. Res. 27: 487-494. 